\title{
A Case of Rhinosporidiosis of the Nasal Cavity
}

\author{
Yong Woo Kim ${ }^{1}$, Sung Ho Choi ${ }^{1}$, Jungsuk $\mathrm{An}^{2}$, and Joo Hyun Jung ${ }^{1}$ \\ ${ }^{1}$ Departments of Otorhinolaryngology-Head \& Neck Surgery, ${ }^{2}$ Pathology, College of Medicine, Gachon University, Gil Hospital, \\ Incheon, Korea
}

\section{우측 비강의 리노스포리듐증 1예 \\ 김용우 ${ }^{1} \cdot$ 최성호 $^{1} \cdot$ 안정석 $^{2} \cdot$ 정주현 $^{1}$ \\ 가천대학교 의과대학 길병원 이비인후-두경부외과학교실, ${ }^{1}$ 병리과학교실 ${ }^{2}$}

\author{
Received February 25, 2016 \\ Revised April 20, 2016 \\ Accepted May 11, 2016 \\ Address for correspondence \\ Jungsuk An, MD, PhD \\ Department of Pathology, \\ College of Medicine, \\ Gachon University, Gil Hospital, \\ 21 Namdong-daero 774beon-gil, \\ Namdong-gu, Incheon 21565, Korea \\ Tel +82-32-460-3824 \\ Fax +82-32-460-2394 \\ E-mail anbox@naver.com \\ Joo Hyun Jung, MD, PhD \\ Department of Otorhinolaryngology- \\ Head \& Neck Surgery, \\ College of Medicine, \\ Gachon University, Gil Hospital, \\ 21 Namdong-daero 774beon-gil, \\ Namdong-gu, Incheon 21565, Korea \\ Tel $+82-32-460-3324$ \\ Fax $+82-32-467-9044$ \\ E-mail bewitch@gilhospital.com
}

Rhinosporidiosis is a chronic granulomatous infectious disease caused by Rhinosporidium seeberi, which is endemic to South India, Sri Lanka, and parts of Africa. It is primarily an infection of the nose. Although involvement of other parts of body has occasionally been reported, it rarely presents as a disseminated disease. We describe a case of nasal rhinosporidiosis in Korea and discuss its clinical manifestations and management.

Korean J Otorhinolaryngol-Head Neck Surg 2016;59(8):624-7

Key Words Infection $\cdot$ Nasal cavity $\cdot$ Polyp $\cdot$ Rhinosporidiosis.

\section{Introduction}

Rhinosporidiosis is a rare chronic granulomatous disease caused by Rhinosporidium seeberi that is characterized by vascular polyps on mucosal surfaces, most commonly in the nasal cavity. ${ }^{1,2)}$ The disease is endemic in south India, Sri Lan$\mathrm{ka}$, and parts of Africa. A few isolated cases have been reported from the United States, South America, Iran, and Nigeria. ${ }^{1)}$ Recent studies have established that the etiological agent is Rhinosporidium seeberi, an aquatic Protist. ${ }^{3)}$ Disseminated rhinosporidiosis is rare. Mucosal involvement of the nose, nasopharynx, and soft palate is the most common presenta- tion. Cutaneous involvement is uncommon and involvement of other areas is unusual. ${ }^{4)}$ Most cases present as nasal obstruction and epistaxis due to the friable polypoid mass in the nasal cavity.

Here, we report a 35-year-old Bangladeshi man with polypoid nasal rhinosporidiosis, the first case of nasal rhinosporidiosis reported in the Republic of Korea.

\section{Case}

A 35-year-old man presented to the ear, nose, and throat clinic of Hospital, Korea, with a history of nasal obstruction, 
Fig. 1. Computed tomography shows a soft tissue density in the right maxillary sinus and nasal cavity: coronal $(A)$ and axial $(B)$ views.

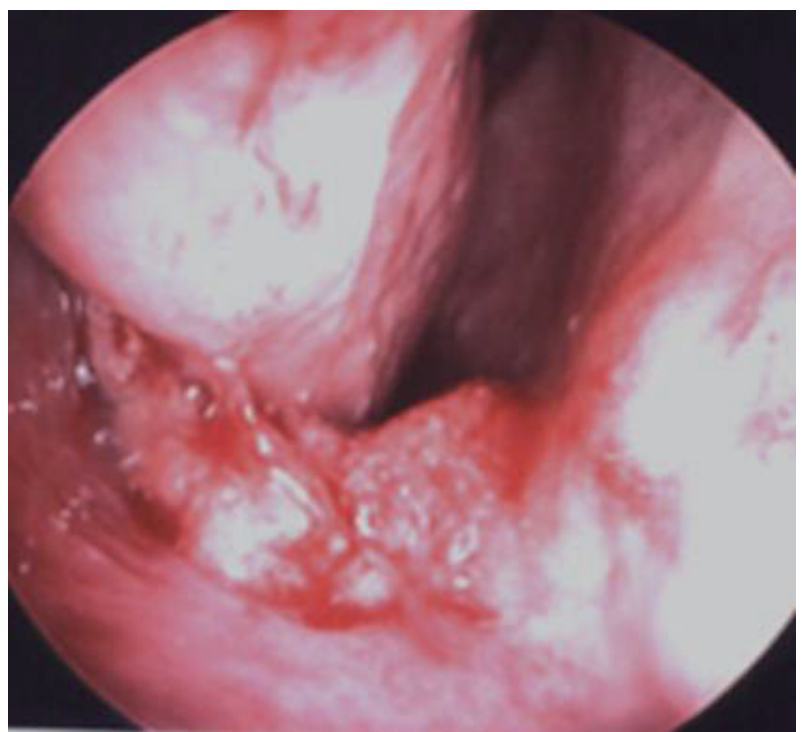

Fig. 2. Irregularly shaped mass on the right inferolateral meatal wall.

facial pain, and mild swelling in the right maxillary area for 6 years. The history was that of a slow-growing mass in the right nasal cavity with increasing nasal blockage. There was no family history of similar disease.

The posteroanterior chest X-ray was normal. Computed tomography of the paranasal sinuses revealed heterogeneous lesions in the right maxillary sinus and mucosal thickening in the right inferior meatus (Fig. 1).

A friable 2-cm-diameter polypoid mass was observed arising from the mucosa on the lateral side of the right inferior meatus (Fig. 2). No abnormality was seen in the left nasal cavity, nasopharynx, or eye. There was no axillary or supraclavicular lymphadenopathy. The working diagnosis was a nasal polyp and to rule out malignancy, hemangioma, and other granulomatous disease.

Under general anesthesia with endotracheal intubation,

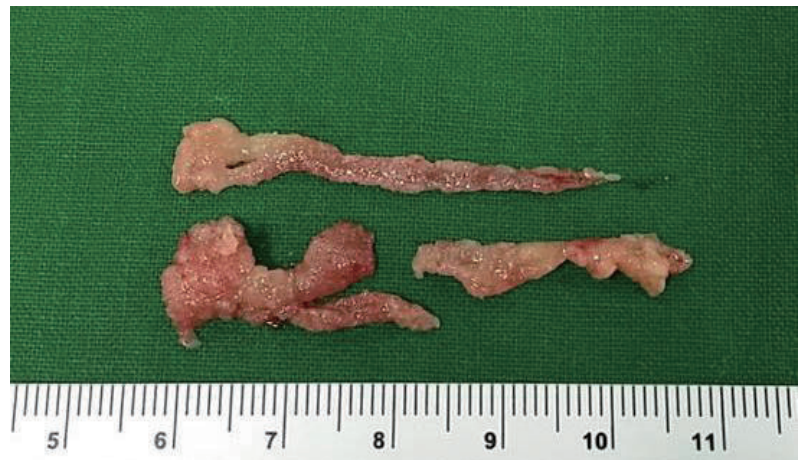

Fig. 3. The mass excised from the nasal cavity.

the mass was excised with $0.5 \mathrm{~cm}$ margin (Fig. 3). The anterior portion of the right inferior turbinate was done medialfracture to better expose the mass. A fragile and polypoid mass was seen broadly based on the right posterior nasal cavity. Bleeding control was done using monopolar electrocautery because of the possibility of remaining endospore. There was moderate bleeding from the mass during surgery. The pathology of the resected mass matched that of the punch biopsy. We removed retention cyst on right maxillary sinus through functional endoscopic sinus surgrey (middle meatal antrostomy, inferior meatal antrostomy) and pathologic report was inflammatory change.

Pathological examination of a punch biopsy showed many globular cysts, each a thick-walled sporangium ranging in size 100 to $500 \mu \mathrm{m}$ in a background of acute and chronic inflammatory cells, covered by hyperplastic squamous epithelium (Fig. 4A). The globular sporangia contained small round endospores $(2-10 \mu \mathrm{m})$, along with many free-lying trophocytes $(10-100 \mu \mathrm{m})$ and inflammatory cells (Fig. 4B). The walls of the sporangia and endospores stained with Gomori methenamine silver (GMS) and Periodic acid Schiff 

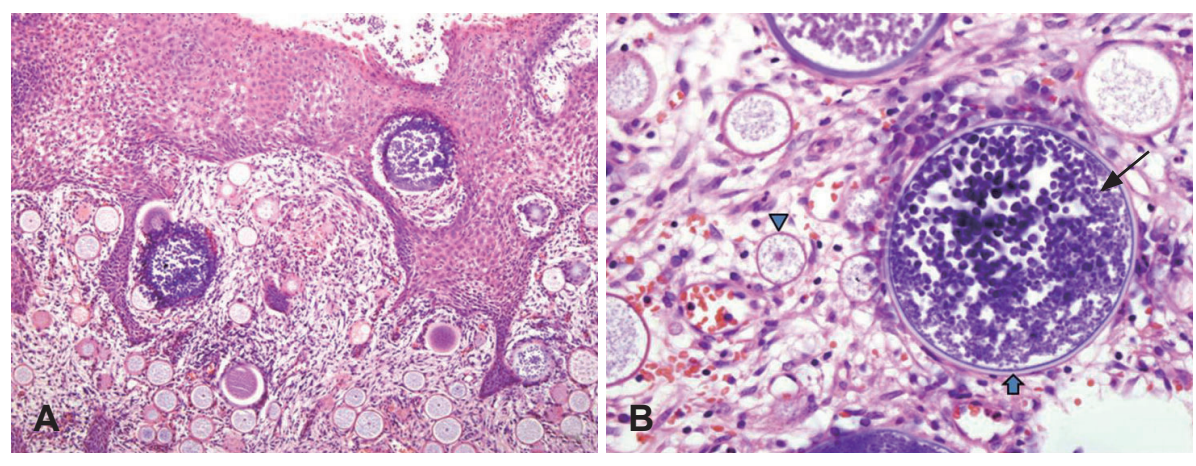

Fig. 4. Histopathological sections showing (A) sporangia and inflammatory cells in a fibromyxomatous stroma covered by stratified squamous epithelium $(H \& E \times 100)$ and (B) sporangia (thick arrow), sporangiospores (narrow arrow), and trophocytes (triangle) in a fibromyxoid stroma (H\&E $\times 400)$.
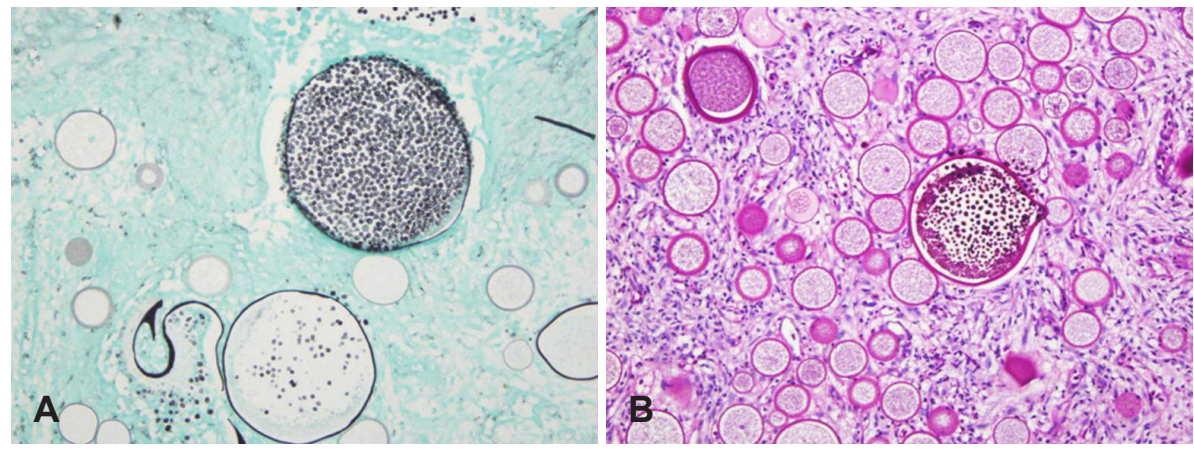

Fig. 5. GMS-positive sporangia and spores $(G M S \times 200)(A)$. PAS-positive sporangia, endospores, and trophocytes (PAS $\times 200)(B)$. GMS: Gomori methenamine silver, PAS: Periodic acid Schiff.
(PAS), while the trophocytes stained poorly or not at all with GMS and PAS (Fig. 5). Hence, the diagnosis of rhinosporidiosis was established and other diseases were ruled out.

The patient was placed on antimicrobial drugs (2nd cephalosporin 14 days) to prevent local secondary bacterial infection. At the 1-year follow-up, he remains healthy with no sign of recurrence.

\section{Discussion}

Rhinosporidiosis is a rare chronic granulomatous disease. Initially described by Seeber in 1900 in an individual from Argentina, rhinosporidiosis is endemic in India, Sri Lanka, South America, and Africa, where the estimated incidence is $1.4 \%$ of the pediatric population. ${ }^{3,5)}$ These polyps are usually unilateral and pedunculated. In a study of 462 cases of rhinosporidiosis in Chhattisgarh, India, an endemic area, the nose and nasopharynx were the most common sites $(81.1 \%)$, followed by ocular tissue (14.2\%). ${ }^{6)}$ Rarely, skin lesions are the predominant manifestation of the disease.

Rhinosporidium seeberi is difficult to culture in vitro, and this has hindered studies of its lifecycle and the precise taxonomy of this organism. Most microbiologists initially considered it a fungus because it stained with fungal stains, such as GMS and PAS. ${ }^{1)}$ Currently, it is believed to be an aquatic Protist belonging to a novel group of fish parasites (Meso- mycetozoa), located phylogenetically between the divergence of fungi and animals. ${ }^{7}$

The presumed mode of infection from the natural aquatic habitat of $R$. seeberi is through traumatized epithelium ("transepithelial infection"), most commonly nasal sites. ${ }^{3)}$ There is evidence for hematogenous spread of rhinosporidiosis to anatomically distant sites. ${ }^{3)}$ The nasal lesions may sometimes present clinically as ulcerated growths, which could mimic malignant lesions, such as sarcomas and carcinomas. ${ }^{3)}$

The definitive diagnosis of rhinosporidiosis is made histopathologically from biopsied or resected tissues, with the identification of the pathogen at different stages, and the demonstration of sporangia and spores. ${ }^{3)}$ The sporangia are large, thick-walled spherical structures containing smaller "daughter cells" (called endospores), seen in a fibromyxoid or fibrous stroma containing chronic inflammatory cells, which include macrophages and lymphocytes, while there are numerous neutrophils around free endospores. ${ }^{3)}$ Each mature sporangium contains an operculum or pore through which the endospores are extruded. ${ }^{3)}$

The various developmental stages of sporangia can be readily identified by using special fungus stains, such as GMS, Gridley's, and PAS stains, although the stages can also be identified with hematoxylin and eosin stain. ${ }^{3)}$

The endospores may be confused with epithelial cells. PAS stain is used to discriminate between endospores and epithe- 
lial cells, in which the cytoplasm and large nuclei can sometimes simulate residual mucoid sporangial material and endospores. ${ }^{3)}$ The endospores stain magenta, while epithelial cells are PAS-negative. ${ }^{3)}$

The curative treatment is surgical excision combined with electrocoagulation. Antifungal and antimicrobial drugs are ineffective, although there has been some success with dapsone. ${ }^{8)}$ The most frequent complications are recurrent dissemination to neighboring anatomical sites and local secondary bacterial infections. ${ }^{9)}$

Unknown host factors may play a role in the development and progression of this disease. ${ }^{3)}$ Although immunosuppression may play a role in progression of the disease, disseminated cases have been reported in immunocompetent patients. ${ }^{10)}$ Our patient was otherwise healthy, and the disease progression was slow.

This is the only reported case of nasal rhinosporidiosis in the Republic of Korea.

We presume that the intrusion of aquatic pathogens of $\mathrm{R}$. seeberi into traumatized epithelium of patient is the route of infection. Routes of infection already introduced are as follows: 1) Autoinoculation, which cause satellite lesions adjacent to granuloma especially in the upper respiratory tract and for local spread, 2) Hematogenous spread, which cause generalized subcutaneous granulomas, 3) Direct inoculation of the organism into traumatized skin. ${ }^{11)}$ We should consider that family members and sexual partner of this patient might have contracted the disease through direct and indirect contacts. It is possible that antigenic variation contributes to immune evasion. ${ }^{3)}$

In conclusion, clinicians and pathologists should keep rhinosporidiosis in mind when managing patients from endemic countries with nasal masses. The cytological appearance of fine needle aspiration smears is distinct and rhinosporidiosis can be diagnosed easily and quickly when suspected.

With the aging Korean population, there are fewer work- ers able to take on strenuous jobs. Consequently, more migrant workers are entering the Korean labor force. Climate change also increases the possibility of catching endemic diseases in Korea, including rhinosporidiosis. It is necessary to check a patient's travel history and family background when diagnosing and treating nasal obstruction and bleeding.

Rhinosporidiosis is likely rare in Korea. If further cases are reported, it will be necessary to follow-up index cases and conduct epidemiological surveillance to determine the prevalence and source of infections in Korea.

\section{REFERENCES}

1) Morelli L, Polce M, Piscioli F, Del Nonno F, Covello R, Brenna A, et al. Human nasal rhinosporidiosis: an Italian case report. Diagn Pathol 2006;1:25

2) Job CK, Karat AB, Karat S. The histopathological appearance of leprous rhinitis and pathogenesis of septal perforation in leprosy. $\mathrm{J}$ Laryngol Otol 1966;80(7):718-32.

3) Arseculeratne SN. Recent advances in rhinosporidiosis and Rhinosporidium seeberi. Indian J Med Microbiol 2002;20(3):119-31.

4) Deshpande AH, Agarwal S, Kelkar AA. Primary cutaneous rhinosporidiosis diagnosed on FNAC: a case report with review of literature. Diagn Cytopathol 2009;37(2):125-7.

5) Moses JS, Balachandran C. Rhinosporidiosis in bovines of Kanyakumari district, Tamil Nadu, India. Mycopathologia 1987;100 (1):23-6.

6) Sudarshan V, Goel NK, Gahine R, Krishnani C. Rhinosporidiosis in Raipur, Chhattisgarh: a report of 462 cases. Indian J Pathol Microbiol 2007;50(4):718-21.

7) Herr RA, Ajello L, Taylor JW, Arseculeratne SN, Mendoza L. Phylogenetic analysis of Rhinosporidium seeberi's $18 \mathrm{~S}$ smallsubunit ribosomal DNA groups this pathogen among members of the protoctistan Mesomycetozoa clade. J Clin Microbiol 1999;37 (9):2750-4.

8) Nair KK. Clinical trial of diaminodiphenylsulfone (DDS) in nasal and nasopharyngeal rhinosporidiosis. Laryngoscope 1979;89(2 Pt 1):291-5.

9) Kumari R, Laxmisha C, Thappa DM. Disseminated cutaneous rhinosporidiosis. Dermatol Online J 2005;11(1):19.

10) Rajeshwari A, Gangadhara S, Deviprasad S, Manohar S. Rhinosporidiosis - a report of two cases. Indian J Otolaryngol Head Neck Surg 2010;62(3):322-5.

11) Nayak S, Acharjya B, Devi B, Sahoo A, Singh N. Disseminated cutaneous rhinosporidiosis. Indian J Dermatol Venereol Leprol 2007;73(3):185-7. 